\title{
Measurement of oceanic chlorophyll by LIDAR, MODIS, fluorometry and above-water radiometry
}

\author{
Milton Kampel*a, João A. Lorenzzetti ${ }^{\mathrm{a}}$, Cristina M. Bentz ${ }^{\mathrm{b}}$, Raul A. Nunes ${ }^{\mathrm{c}}$, Rodolfo Paranhos ${ }^{\mathrm{d}}$, \\ Frederico M. Rudorff ${ }^{\mathrm{a}}$, Alexandre T. Politano ${ }^{\mathrm{b}}$ \\ ${ }^{a}$ Instituto Nacional de Pesquisas Espaciais, PO Box 515, Sao Jose dos Campos, Brazil, 12201-970; \\ ${ }^{\mathrm{b}}$ PETROBRAS, Research and Development Center, Rio de Janeiro, Brazil, 21949-900; \\ ${ }^{\mathrm{c}}$ PUC-Rio, PO Box 38008, Rio de Janeiro, Brazil, 22453-900; \\ ${ }^{\mathrm{d}}$ Universidade Federal do Rio de Janeiro, Rio de Janeiro, Brazil, 21941-590.
}

\begin{abstract}
Comparisons between in situ measurements of surface chlorophyll concentration (CHL) and ocean color remote sensing estimates were conducted during an oceanographic cruise in the Brazilian Southeastern continental shelf and slope in November 2004. In situ estimates were based on fluorometry, above-water radiometry and lidar fluorosensor. Three empirical algorithms were used to estimate chlorophyll a concentration from radiometric measurements: Ocean Chlorophyll 3 bands (OC3M), Ocean Chlorophyll 4 bands (OC4v4), and Ocean Chlorophyll 2 bands (OC2v4). The satellite estimates of chlorophyll $a$ were derived from data collected by the Moderate-resolution Imaging Spectroradiometer (MODIS) with a nominal $1.1 \mathrm{~km}$ resolution at nadir. Three algorithms were used to estimate chlorophyll concentrations from MODIS data: one empirical - OC3M, and two semi-analytical - Garver, Siegel, Maritorena version 01 (GSM01), and Carder. In this paper, LIDAR, MODIS and in situ above-water radiometry and fluorometry are briefly described and the estimated values of chlorophyll retrieved by these techniques are compared. Chlorophyll concentrations were fairly well estimated by all the methods. In general, the empirical algorithms applied to the satellite and in situ radiometric data showed a tendency for overestimating CHL. The semi-analytical GSM01 algorithm applied to MODIS data performed better than the Carder and the empirical OC3M algorithms.
\end{abstract}

Keywords: Chlorophyll, LIDAR, MODIS, above-water radiometry, fluorometry

\section{INTRODUCTION}

Ocean color remote sensing has changed our perspective of ocean observation. Global maps of surface chlorophyll concentration (CHL), and therefore, of phytoplankton primary productivity can be routinely produced ${ }^{1,2}$. However, these products are based on the application of sometime complex bio-optical algorithms ${ }^{3}$, including atmospheric correction models ${ }^{4}$, on the water leaving radiances measured by the remote sensors. Therefore, satellite images must be calibrated and validated with the use of in situ instruments from research ships, moored buoys and drifters, for example ${ }^{3}$.

Satellite images have been systematically used for monitoring the oceanic environment on the Brazilian Southeastern continental margin. Aiming to advance scientifically and technically the current remote sensing data analysis procedures a two years research project - FITOSAT is being jointly conducted by INPE, PETROBRAS R\&D Center and other universities. One of the phases of this project involved an oceanographic cruise with the simultaneous acquisition of in situ and remote sensing data in the Campos Basin region. The simultaneous data acquisition enabled the meteooceanographic contextualization of the in situ data collection and allowed the evaluation of the remote sensing products.

In this context, in situ estimates of CHL were obtained with fluorometry, above-water radiometry and lidar fluorosensor. The satellite estimates of CHL were derived from MODIS data. In this article, these different methods are briefly described and their results are statistically compared.

*milton@dsr.inpe.br; phone 5512 39456501; fax 5512 39456488; www.inpe.br

Coastal Ocean Remote Sensing, edited by Robert J. Frouin, ZhongPing Lee, Proc. of SPIE Vol. 6680, 66800H, (2007) · 0277-786X/07/\$18 - doi: 10.1117/12.736967 


\section{METHODOLOGY}

\subsection{In situ Chlorophyll}

Chlorophyll measurements were measured in 18 stations during a cruise held in November 2004. The study area includes the continental shelf and slope of the Brazilian Southeastern region, from Cape Sao Tome to Cabo Frio $\left(22^{\circ} \mathrm{S}\right)$, at Campos Basin, Rio de Janeiro (Figure 1). Phytoplankton abundance was estimated from $2 \mathrm{~L}$ of surface samples filtered through Millipore cellulose membranes $(0.45 \mu \mathrm{m})$. The filters were kept in liquid nitrogen and the chlorophyll $a$ concentrations determined after extraction in acetone $90 \%$, for 18 hours at $4^{\circ}$ in a Turner TD-700 fluorometer 5 .

\subsection{In situ Radiometry}

Above water radiometric measurements were obtained with a hyperspectral SPECTRON SE590 radiometer in 31 stations (Figure 1). Each radiance spectrum was sampled between $400-800 \mathrm{~nm}$, with a $5 \mathrm{~nm}$ resolution. The protocol adopted for the measurements was the one proposed by Fougnie et al. ${ }^{6}$, with a polarizer filter. The radiometric data were numerically integrated to simulate the spectral bands of SeaWiFS and MODIS orbital sensors, by the trapezoidal rule. The remote sensing reflectance, $R_{R S}(\lambda)$, was calculated by the following equation:

$$
R_{R S}=\frac{L_{w}(\lambda)}{E_{d}(\lambda)}
$$

where $L_{w}(\lambda)$ is the water leaving spectral radiance and $E_{d}(\lambda)$ is the downwelling spectral irradiance incident on the sea surface. $E_{d}(\lambda)$ was estimated by the radiance $L(\lambda)$ reflected by a Spectralon plate ${ }^{7}$, as follows:

$$
E_{d}(\lambda)=L(\lambda) f_{c} \pi
$$

where $f_{c}$ is a correction factor estimated in the laboratory by the ratio of $L_{r e f}(\lambda)$ of a standard reference (approximately $100 \%$ ) by the Spectralon plate's $L(\lambda)$ used in the field.

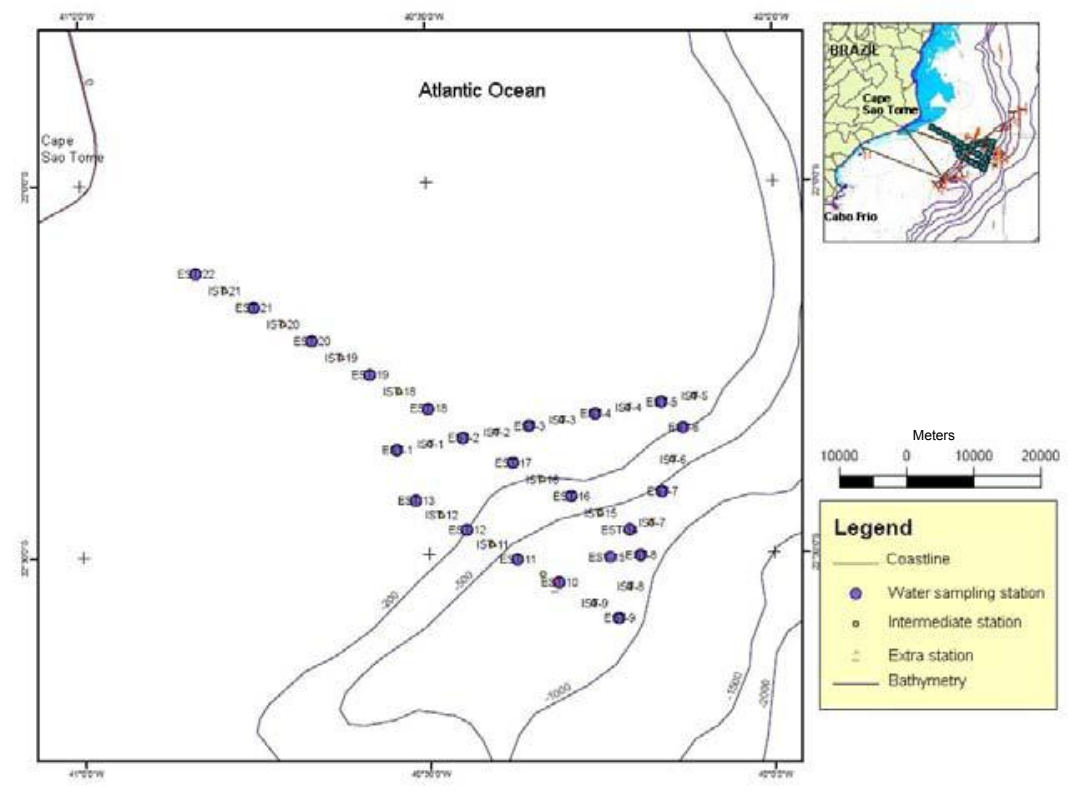

Fig. 1. Study area and field stations occupied during November 2004 at the Brazilian Southeastern continental margin. Isobaths in meters. Water sampling, above-water radiometry and LIDAR stations labeled with an " $E$ ". Stations without water sampling labeled with an " $P$ ". 
The SeaWiFS empirical algorithms Ocean Chlorophyll 4-bands - OC4v4 and Ocean Chlorophyll 2-bands - OC2v4, and the MODIS algorithm Ocean Chlorophyll 4-bands - OC3M were applied to the radiometric data to estimate CHL.

The OC2v4 algorithm estimates CHL based on a band ratio of $R_{R S}(490) / R_{R S}(555)$ using a modified cubic polynomial function ${ }^{3}$ :

$$
C H L=10,0^{\left(0,319-2,336 R_{2 S}+0,879 R_{2 S}^{2}-0,135 R_{2 S}^{3}\right)-0,071}
$$

where $R_{2 S}=\log _{10}\left(R_{555}^{490}\right)$.

The algorithm OC4v4 also relates a band ratio with CHL using a polynomial function, but is based on the maximum band ratio determined as the highest ratio $\left(R_{\max }\right)$ between the values of $R_{R S}(443) / R_{R S}(555), R_{R S}(490) / R_{R S}(555)$, and $R_{R S}(510) / R_{R S}(555)$ through the following function of forth order ${ }^{3}$ :

$$
C H L=10,0^{\left(0,366-3,067 R_{4 S}+1,930 R_{4 S}^{2}-0,649 R_{4 S}^{3}-1,532 R_{4 S}^{4}\right)}
$$

where $R_{4 S}=\log _{10}\left(R_{\max }\right)$.

The algorithm OC3M also uses a polynomial function of forth order from $R_{\max }$ between $R_{R S}(443) / R_{R S}(550)$ and $R_{R S}(490) / R_{R S}(550)$, through the following equation ${ }^{3}$ :

$$
C H L=10,0^{\left(0,283-2,753 R_{3 M}+1,457 R_{3 M}^{2}-0,659 R_{3 M}^{3}-1,403 R_{3 M}^{4}\right)}
$$

where $R_{3 M}=\log _{10}\left(R_{\max }\right)$.

\subsection{LIDAR}

The PUC-Rio Fluorosensor LIDAR system uses the excitation at $532 \mathrm{~nm}$ of the doubled frequency radiation (second harmonic) of Nd:YAG laser as light source. A rotating rectangular metal mirror directs the probing beam to the water surface by means of a hole. This mirror deflects the water backscattered signal to a $200 \mathrm{~mm}$-diameter Newton-type reflecting telescope, which is filtered in order to eliminate elastic backscattering. This return signal passes through the entrance slit of the polychromator, which is assembled as an auto collimation lens focusing system. To detect the spectrum of the return signal, we use a CCD array camera with Peltier cooling, 1024 elements.

Two types of radiation are collected: one is the water-Raman backscattering (occurs at $655 \mathrm{~nm}$ ) and the other is the fluorescence radiation generated when the source interacts with the fluorescent elements present in the water. This wavelength excites the fluorescence of chlorophyll, in a band centered at $685 \mathrm{~nm}$, and of DOM, in a region from 540 to $620 \mathrm{~nm}$. Over 13.000 spectra were obtained during the campaign, with the LIDAR installed at the gangway of the AstroGaroupa vessel. In order to validate each spectrum, an analysis of the power spectrum of its Fourier transformation was made, and then a validation criterion of these spectra was established. Of the total number of spectra collected during the vessel's course between the November 21st and 25th, 9.511 of them are being objects of analysis.

The intensities of the chlorophyll bands $\left(I_{c l}\right)$ were calculated according to the method developed by Barbosa ${ }^{8}$ to the equipment. The values of CSM were attained by means of an adjustment using calibration parameters obtained via laboratorial analysis of samples collected on a prior cruise at the same region where an event of algae flowering occurred. The calibration used is given by:

$$
C H L_{L I D A R}=4,9 *\left(I_{c l}\right)-0,175
$$

\subsection{Remote sensing}

Ocean color remote sensing images acquired by MODIS sensor during the same period of the oceanographic cruise were processed as CHL fields with the application of one empirical and two semi-analytical algorithms. The MODIS sensor has 36 spectral bands, with 8 dedicated to ocean color applications. These bands have a spatial nominal resolution of to $1.1 \mathrm{~km}$ and a temporal resolution of 1-2 days.

Level 1 MODIS images were acquired locally by INPE's receiving station and processed using SeaDAS software distributed by NASA. Initially, the data were radiometrically calibrated to generate the water normalized upwelling 
radiances. The images considered of interest were selected in accordance to the study area. Atmospheric correction algorithms ${ }^{4}$ were applied to each image before the calculation of CHL values.

As mentioned before, the OC3M empirical algorithm ${ }^{3}$, and two semi-analytical algorithms, Garver, Siegel, Maritorena version $01-\mathrm{GSM}^{9} 1^{9}$, and $\mathrm{Carder}^{10}$ were applied to estimate CHL with MODIS data. Maritorena et al. (2002) ${ }^{9}$ presented a protocol to improve the semi-analytical model initially proposed by Garver and Siegel $(1997)^{11}$, for global applications. The complete formulation of the model can be expressed as the following:

$$
L_{W N}(\lambda)=\frac{t F_{0}(\lambda)}{n_{w}^{2}} \sum_{i=1}^{2} g_{i}\left\{\frac{b_{b w}(\lambda)+b_{b p}\left(\lambda_{0}\right)\left(\lambda / \lambda_{0}\right)^{-\eta}}{b_{b w}(\lambda)+b_{b p}\left(\lambda_{0}\right)\left(\lambda / \lambda_{0}\right)^{-\eta}+a_{w}(\lambda)+C h l_{p h}^{*}(\lambda)+a_{c d m}\left(\lambda_{0}\right) \exp \left[-S\left(\lambda-\lambda_{0}\right)\right]}\right\}
$$

where $L_{W N}$ is the normalized water leaving radiance, $t$ is the air-sea transmission factor; $F_{0}(\lambda)$ is the extra-terrestrial solar irradiance; $n_{w}$ is the refraction index of water; $g_{l}=0.0949 \mathrm{sr}^{-1}$ and $g_{2}=0.0794 \mathrm{sr}^{-1} ; b b_{w}(\lambda)$ is the backscattering of water; $a_{w}(\lambda)$ is the absorption by water; $b b_{p}(\lambda)$ is the backscattering by particles; $C h l_{p h}^{*}$ is the chlorophyll- $a$ specific absorption coefficient; $S$ is the spectral decay for the dissolved matter and detritus absorption $(\mathrm{cdm}) ; \eta$ is the exponent of the power law for the particulate backscattering coefficient; $\lambda_{0}$ is the wavelength $443 \mathrm{~nm}$ wavelength.

The Carder algorithm ${ }^{10}$ utilizes a more complex approach. The components associated with the absorption of the pigments are divided from those associated with the degradation products (for example, gelbstoff and detritus, $a_{g}^{*}(\lambda)$ ). The absorption coefficient of phytoplankton chlorophyll, $a_{p h}^{*}(\lambda)$, is adjusted in relation to the chlorophyll concentration and the availability of light and nutrients. The distinction between the effects of the principal constituents is obtained by the spectral differences between $a_{p h}^{*}(\lambda)$ and $a_{g}^{*}(\lambda)$. Comparing sea surface temperature with nitrate depletion temperature (NDT) ${ }^{12}$, the presence of big cells rich in chlorophyll and small cells poor in chlorophyll can be deduced from the satellite data ${ }^{10}$. The chlorophyll rich cells with low values of $a_{p h}^{*}(\lambda)$, i.e., with packed pigments, occurs generally in ambient with low level of light and rich in nutrients. On the other hand, chlorophyll poor cells but with high values of $a_{p h}^{*}(\lambda)$, i.e., without packaging, are present in ambient replete of photons, but poor in nutrients. During the development and validation of the Carder algorithm, in situ data sets were compartmented into 2 regions. In the first, the pigment packaging would not be expected, and a second one where this packaging effect would probably occur more frequently or more intensely. Besides, a global average algorithm was developed to be used in conditions where the packaging effect is unknown or transitional. The algorithm also alternates between the empirical and the semi-analytical formulation, using different coefficients for the varying levels of pigment packaging.

\subsection{Statistical comparisons}

The comparisons obtained between the in situ CHL and those estimated with MODIS data were calculated inside a window of 12 hours window. The pairs of data were composed between the $C H L_{\text {insitu }}$ and the median value of a $3 \times 3$ pixels $\left(9 \mathrm{~km}^{2}\right)$ centered on the geographical position of the sampling station in the equivalent MODIS image. The fluorometric data were statistically compared to the satellite estimates, above-water radiometric data and LIDAR data, through linear regression analysis, root mean square error, and transformed-rmse $(r m s e-L)^{10}$.

\section{RESULTS AND DISCUSSION}

$C H L_{\text {insitu }}$ values varied between 0.077 and $0.197 \mathrm{mgm}^{-3}$ with a mean value of $0.12( \pm 0.04) \mathrm{mgm}^{-3}$. These low values are typical of the oligotrophic waters of the Brazil Current (BC) as observed previously by other authors ${ }^{13,14}$.

In general, the empirical algorithms applied to the in situ radiometric data overestimated $C H L_{\text {insitu }}$ (Figure 2). OC3M and OC4v4 presented a similar performance, with lowest rmse-L (0.28) and rmse (0.93) than OC2v4 (0.40 and 1.36 , respectively) (see Table 1).

For illustration, examples of MODIS images processed using with the 3 algorithms tested in this study are shown (Figure 3 ). In the 11/25/2004 image, the oligotrophic waters of the $\mathrm{BC}$ are observed offshore, over the slope region, in dark blue colors $\left(\mathrm{OC} 3 \mathrm{M}<0.08 \mathrm{mgm}^{-3}\right.$; GSM01<0.08 $\mathrm{mgm}^{-3}$; Carder $\left.<0.1 \mathrm{mgm}^{-3}\right)$. A surface signature of a mesoscale eddy with a mean diameter of $75-80 \mathrm{~km}$ was identified in front of Cape Sao Tome between $22.00^{\circ} \mathrm{S}-22.65^{\circ} \mathrm{S}$, and $39.9^{\circ} \mathrm{W}$ $40.77^{\circ} \mathrm{W}$, with relatively higher CHL values $\left(0.1<\mathrm{OC} 3 \mathrm{M}<0.15 \mathrm{mgm}^{-3} ; 0.08<\mathrm{GSM} 01<0.13 \mathrm{mgm}^{-3} ; 0.2<\mathrm{Carder}<0.3 \mathrm{mgm}^{-}\right.$ $\left.{ }^{3}\right)$. 
Table. 1. Comparison between different in situ and satellite estimates of surface chlorophyll- $a$ concentration in the Brazilian Southeastern continental shelf and slope waters in November 2004. $(\mathrm{N}=$ number of observations; $\mathrm{RAD}=$ in situ radiometry; SAT = MODIS data).

\begin{tabular}{|c|c|c|c|}
\hline Algorithm/LIDAR & rmse-L & rmse & $\mathbf{N}$ \\
\hline $\mathrm{OC} 2 \mathrm{v} 4_{\mathrm{RAD}}$ & 1.36 & 0.40 & 17 \\
\hline $\mathrm{OC} 4 \mathrm{v} 4_{\mathrm{RAD}}$ & 0.93 & 0.28 & 17 \\
\hline $\mathrm{OC} 3 \mathrm{M}_{\mathrm{RAD}}$ & 0.93 & 0.28 & 17 \\
\hline OC $3 \mathrm{M}_{\mathrm{SAT}}$ & 0.36 & 0.11 & 10 \\
\hline GSM01 1 SAT & 0.28 & 0.08 & 10 \\
\hline Carder $_{\mathrm{SAT}}$ & 1.14 & 0.34 & 10 \\
\hline $\mathrm{CSM}_{\text {LIDAR }}$ & 0.48 & 0.14 & 14 \\
\hline
\end{tabular}

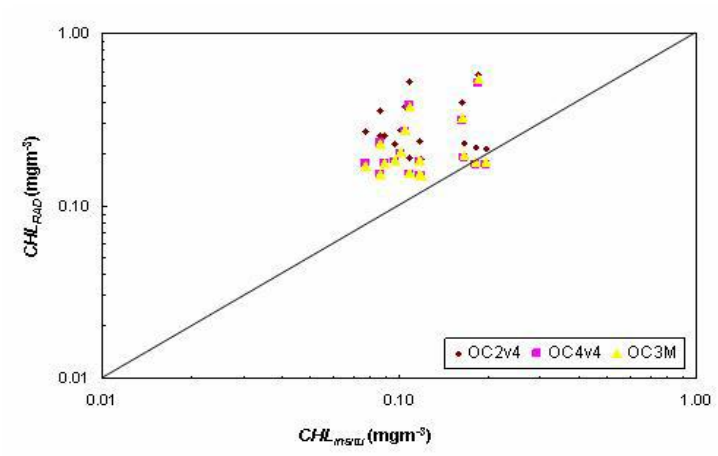

(a)

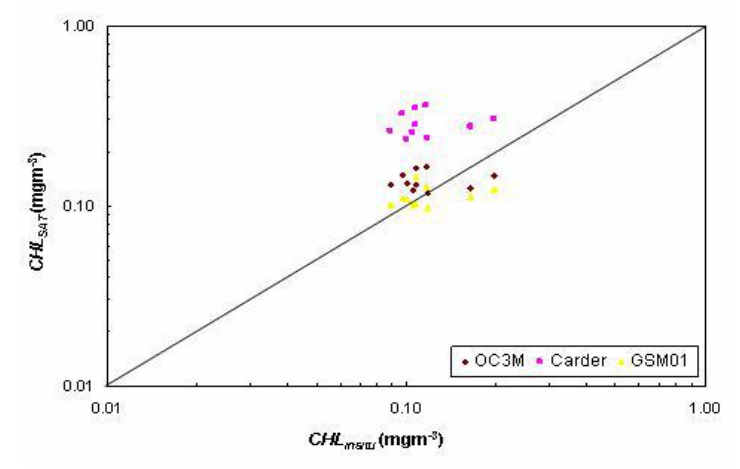

(b)

Fig. 2. Scatter plots of chlorophyll concentration estimates obtained with (a) above-water radiometric data (3 algorithms), and (b) MODIS ocean color remote sensing data ( 3 algorithms) against in situ fluorometric estimates.

Ocean color satellite estimates also overestimated the values of $C H L_{\text {insitu }}$ (Figure 2), although the algorithms GSM01 and OC3M have underestimated the relatively higher concentrations. The best performance was obtained with the semianalytical algorithm GSM01, with the lowest values of rmse-L (0.28) and rmse (0.08), respectively (see Table 1$)$. The empirical algorithm OC3M also presented a good performance, with rmse- $L$ equal to 0.36 and rmse of 0.11 .

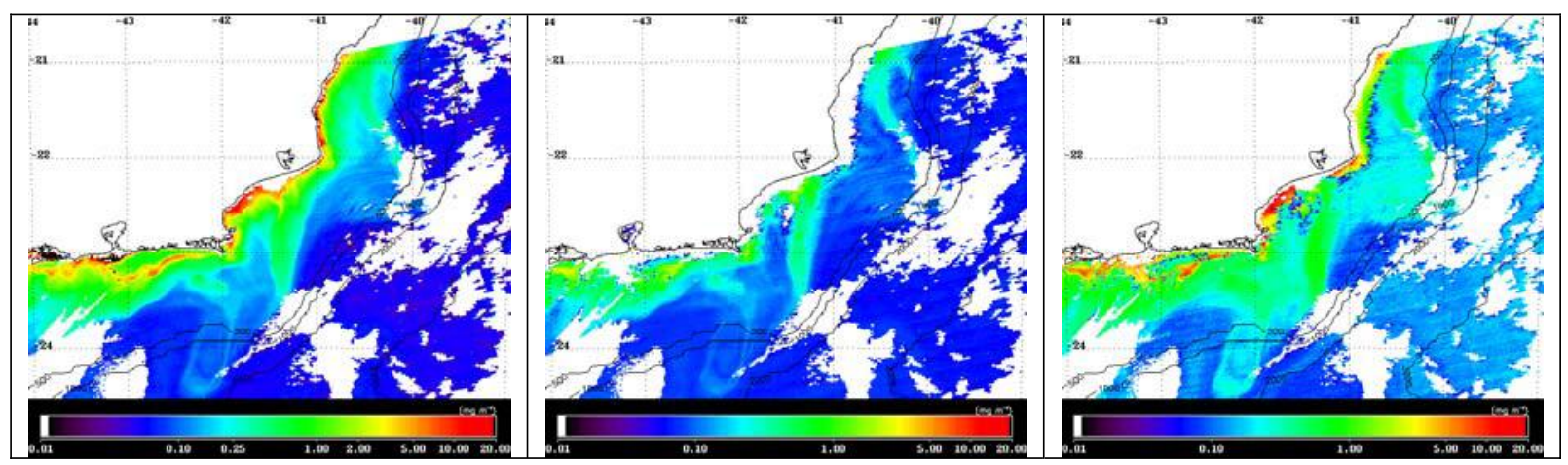

Fig. 3. Surface distributions of chlorophyll concentration estimated with OC3M (left), GSM01 (center), and Carder (right) algorithms applied to MODIS data acquired on 11/25/2004 (see text for details). Isobaths in meters. Color table in logarithmic scale. Land and clouds are masked in white.

The spectral distributions of $R_{R S}$ measured in 31 stations are shown on Figure 4. In general, all the spectra are typical of Case 1 oceanic and oligotrophic waters with low chlorophyll concentrations. At station I03 (yellow on Figure 4) the highest chlorophyll value was obtained with the LIDAR $\left(0.22 \mathrm{mgm}^{-3}\right)$, which was similar to those estimated by the OC3M and OC4v4 algorithms applied to the in situ radiometric data ( 0.18 and $0.19 \mathrm{mgm}^{-3}$, respectively). The noise also 
observed at station E05 (dark blue on Figure 4) was due to the low light level at the time of data acquisition. The different shape of the spectrum at station E21 corresponds to more coastal waters, with relatively higher chlorophyll concentration $\left(0.54 \mathrm{mgm}^{-3} \mathrm{OC} 3 \mathrm{M}\right)$ and with the probable presence of other optically active components.

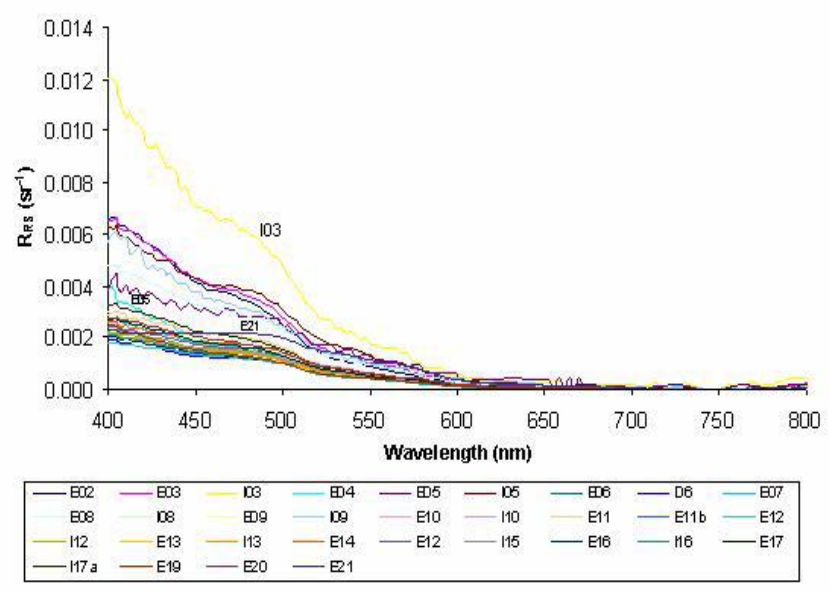

Fig. 4. Surface Remote sensing reflectance spectra obtained by above-water radiometry during the cruise FITOSAT I cruise, November 2004, in the Brazilian Southeastern continental shelf and slope. Water sampling, above-water radiometry and LIDAR stations labeled with an " $E$ ". Stations without water sampling labeled with an " $P$ " (see text).

The fluorescence spectra processed from the LIDAR data are presented on Figure 5. The chlorophyll concentrations estimated with the LIDAR $\left(C S M_{\text {LIDAR }}\right)$ at the stations with simultaneous water sampling for fluorometric analysis varied between 0.064 and $0.0163 \mathrm{mgm}^{-3}$, with a mean value of $0.12( \pm 0.03) \mathrm{mgm}^{-3}$, very similar to $C S M_{\text {insitu }}$. In fact, a paired ttest confirmed that the two mean values are statistically equal. The performance of the LIDAR was similar to that obtained by the in situ fluorometric and radiometric methods, with rmse and rmse- $L$ values of 0.14 and 0.48 , respectively.

\section{CONCLUSIONS}

To our best knowledge this is the first published result of simultaneous measurements of surface chlorophyll concentration in the Brazilian Southeastern continental shelf and slope region using in situ fluorometric, above-water radiometry, and LIDAR, complemented with ocean color remote sensing MODIS imagery.

Chlorophyll concentrations were reasonably well estimated by the methods utilized, even though, the empirical algorithms applied to the in situ radiometric and satellite data have slightly overestimated the CHL values. The semianalytical GSM01 algorithm applied to MODIS data presented the best performance in relation to the OC3M and Carder algorithms.

Other comparisons between the above-water radiometric data, LIDAR and satellite data are being conducted in order to better explore those sampling techniques and to advance in the ecosystemic study of the interest area. 


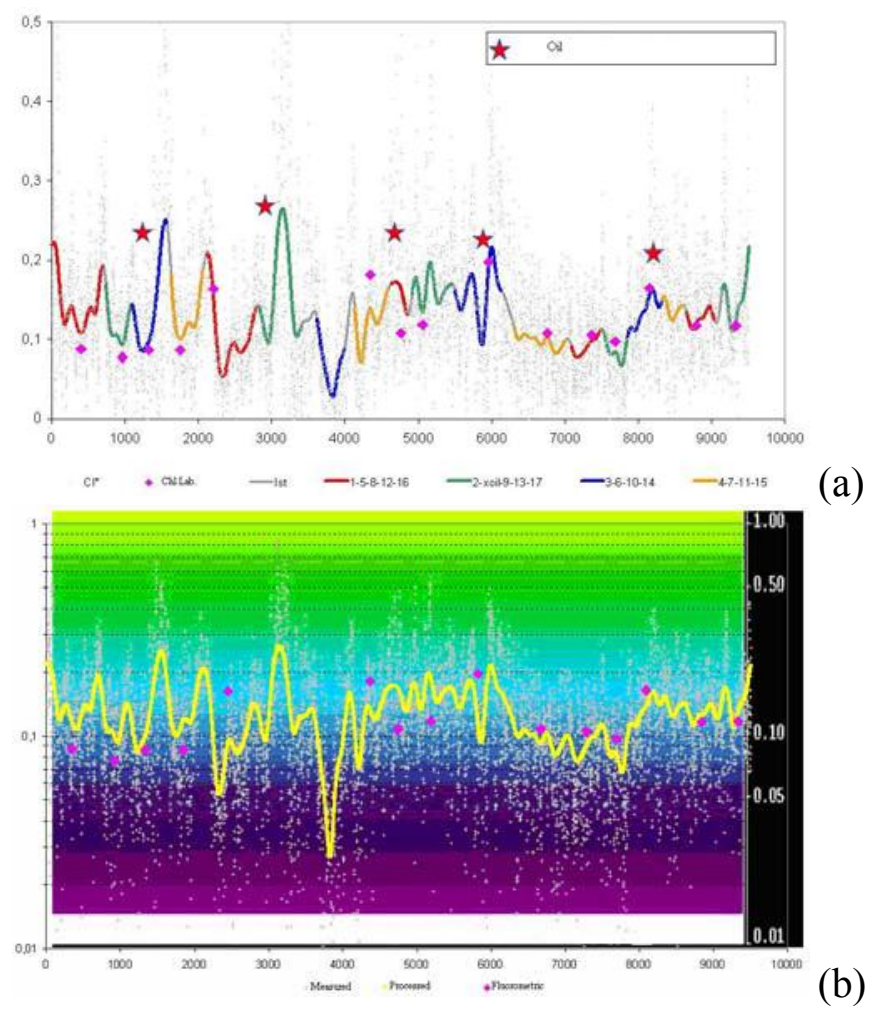

Fig. 5. Surface along-track chlorophyll concentration estimated with the LIDAR during the cruise FITOSAT I cruise, November 2004, in the Brazilian Southeastern continental shelf and slope. (a) Colors indicates the water sampling stations; stars indicates the occurrence of oil slicks; (b) LIDAR estimates superposed to the logarithmic scale used for MODIS images. Purple diamonds represent the fluorometric estimates.

\section{ACKNOWLEGMENTS}

This work was supported by the PETROBRAS R\&D Center, the National Space Research Institute (INPE), and institutions involved in the FITOSAT Project, including the Federal University of Rio de Janeiro and the Catholic University of Rio de Janeiro. NASA provided the satellite images and SeaDAS software. The authors would like to thanks the crew of R/C Astro Garoupa, researchers and students that participated in the field work.

\section{REFERENCES}

1. P.G. Falkowski and J.A. Raven, Aquatic Photosynthesis. Malden: Blackwell, 1997. 375 p.

2. M.J. Behrenfeld and P.G. Falkowski, Photosynthetic rates derived from satellite-based chlorophyll concentration. Limnol. Oceanogr., 42, 1-20 (1997).

3. J.E. O'Reilley; S. Maritorena; M.C. O'Brien; D.A. Siegel; D. Toole; D. Menzies; R.C. Smith; J.L. Mueller; B.G. Mitchell; M. Kahru; R.P. Chavez; P. Strutton; G.F. Cota; S.B. Hooker; C.R. McClain; K.L. Carder; F. Mueller-Karger; L. Harding; A. Magnusion; D. Phynney; G.F. Moore; J. Aiken; K.R. Arrigo; R. Letelier; M. Culver, SeaWiFS Postlaunch Calibration and Validation Analyses, Part 3, Volume 11. In: S. B. Hooker e E. R. Firestone (ed). NASA Tech. Memo. 2000-2206892. Greenbelt, Md, NASA Goddard Space Flight Center, (2000).

4. H.R. Gordon and M. Wang, Retrieval of water-leaving radiance and aerosol optical thickness over the oceans with SeaWiFS: a preliminary algorithm. Applied Optics, 33, 443-452 (1994).

5. T.R. Parsons; Y. Maita; C.M. Lalli, A manual of chemical and biological methods for seawater analysis, Pergamon Press, Oxford, 173p., 1984.

6. B. Fougnie; R. Frouin; P. Lecomte; P.-Y. Deschamps, Reduction of skylight reflection effects in the above-water measurement of diffuse marine reflectance. Applied Optics, 38(18), 3844-3856 (1999). 
7. C.D. Mobley, Estimation of the remote-sensing reflectance from above-surface measurements. Applied Optics, 38(36), 7442-7455 (1999).

8. P.C.C. Barbosa, Aplicações de Fluorescência Induzida por Laser em Monitoramento Ambiental. 2003. 139p. (PUCRio, No 9916186/CA). PhD Thesis (in portuguese), Pontifícia Universidade Católica do Rio de Janeiro.

9. S. Maritorena; D.A. Siegel; A.R. Peterson, Optimization of a semi-analytical ocean color model for global-scale applications. Applied Optics, 41, 2705-2714 (2002).

10. K.L. Carder; F.R. Chen; J.P. Cannizzaro; J.W. Campbell; B.G. Mitchell Performance of the MODIS semi-analytical ocean color algorithm for chlorophyll-a. Advances in Space Research, 33(7), 1152-1159 (2004).

11. S.A. Garver and D.A. Siegel, Inherent optical property inversion of ocean color spectra and its biogeochemical interpretation. I. Time series from the Saragasso Sea. Journal Geophysical Research, 102, 18607-18625 (1997).

12. D. Kamykowski, A preliminary biophysical model of the relationship between temperature and plant nutrients in the upper ocean. Deep-Sea Research I, 34, 1067-1079 (1987).

13. M. Kampel, Estimativa da produção primária e biomassa fitoplanctônica através de sensoriamento remoto da cor do oceano e dados in situ na costa sudeste brasileira. PhD Thesis, Universidade de São Paulo, Instituto Oceanográfico, São Paulo, 272p. (2003).

14. S.A. Gaeta; P.M. Metzler; R.M. Lopes, Plâncton e produtividade primária na plataforma da costa norte do Estado do Rio de Janeiro-Campanha de verão (dez/91-jan/92). Relatório do Projeto Monitoramento Oceânico da Bacia de Campos FUNDESPA/GEOMAP-PETROBRÁS, (1993). 